\begin{tabular}{|l|l|l|l|l|}
$\begin{array}{l}\text { Journal of } \\
\text { Endocrinology }\end{array}$ & $\begin{array}{l}\text { Resistin regulates neuronal } \\
\text { autophagy }\end{array}$ & $\mathbf{2 3 8 : 1}$ & $\mathbf{7 7 - 8 9}$ \\
\hline
\end{tabular}

RESEARCH

\title{
Resistin inhibits neuronal autophagy through Toll-like receptor 4
}

\author{
Jie Miao',2,3, Yacir Benomar1,2, Sarah Al Rifai1, Ghislaine Poizat1,2, Laure Riffault1,2, Delphine Crépin1,2 and \\ Mohammed Taouis ${ }^{1,2}$ \\ IUMR 9197, Molecular Neuroendocrinology of Food Intake, University Paris-Sud, University Paris-Saclay, Orsay, France \\ 2Department of Molecules and Circuits, CNRS UMR 9197, Molecular Neuroendocrinology of Food Intake, Paris-Saclay Institute of Neuroscience, \\ Orsay, France \\ 3Department of Geriatrics, Ruijin Hospital, Shanghai Jiao Tong University, School of Medicine, Shanghai, China \\ Correspondence should be addressed to M Taouis: mohammed.taouis@u-psud.fr
}

\section{Abstract}

Autophagy is a non-selective degradation pathway induced in energy-deprived cells and in non-starved cells by participating in cellular inflammatory responses mainly through the elimination of injured and aged mitochondria that constitute an important source of reactive oxygen species. We have previously reported that resistin/TLR4 signaling pathway induces inflammation and insulin resistance in neuronal cell. However, the impact of resistin-induced inflammation on neuronal autophagy is unknown. In the present study, we hypothesized that resistin-induced neuroinflammation could be attributed, at least partially, to the impairment of autophagy pathways in neuronal Key Words
- autophagy
- resistin
- TLR4
- neurons
- hypothalamus
signaling cells. Our data show that resistin decreases neuronal autophagy as evidenced by the repression of the main autophagy markers in SH-SY5Y human neuroblastoma cell line. Furthermore, the silencing of TLR4 completely abolished these effects. Resistin also inhibits AMPK phosphorylation and increases that of Akt/mTOR contrasting with activated autophagy where AMPK phosphorylation is augmented and mTOR inhibited. In vivo, resistin treatment inhibits the mRNA expression of autophagy markers in the hypothalamus of WT mice but not in T/r4-I- mice. In addition, resistin strongly diminished LC3 (a marker of autophagy) labeling in the arcuate nucleus of WT mice, and this effect is abolished in T/r4-/- mice. Taken together, our findings clearly reveal resistin/TLR4 as a new regulatory pathway of neuronal autophagy.

Journal of Endocrinology (2018) 238, 77-89

\section{Introduction}

Resistin is described as a potential factor in obesitymediated insulin resistance and type 2 diabetes (Savage et al. 2001, Steppan et al. 2001). Resistin is a cysteinerich peptide secreted by adipose tissue in rodents and humans and macrophages in humans (Savage et al. 2001, Patel et al. 2003), promoting inflammation and insulin resistance (Savage et al. 2001, Mojiminiyi \& Abdella 2007). Furthermore, plasma resistin levels are increased in obese insulin-resistant rodents and humans (Savage et al. 2001, Olefsky \& Glass 2010), while fasting decreases resistin mRNA expression $(5,6)$. In addition, resistin gene deletion or infusion of resistin antibodies or antisense oligonucleotides restores insulin responsiveness (Savage et al. 2001, Muse et al. 2004, Satoh et al. 2004, Qi et al. 2006). Resistin has been also linked to other pathologies such as atherosclerosis (Reilly et al. 2005). These effects are mainly attributed to the peripheral action of resistin; however, resistin expression and action have been reported 
in hypothalamic neurons (Brunetti et al. 2004, Wilkinson et al. 2005, Benomar et al. 2013) suggesting a potential role of resistin in the brain. Indeed, central resistin modulates glucose/lipid metabolism and food intake and impairs liver insulin sensitivity (Muse et al. 2007, Vasquez et al. 2008). Resistin also modulates the synthesis and secretion of key pro-inflammatory cytokines such as TNF- $\alpha$, IL- 6 and IL12 in macrophages via a nuclear factor-кB (NF-кB)-dependent pathway (Rajal et al. 2003, Olefsky \& Glass 2010). We have recently reported that central resistin treatment inhibited insulin signaling and promoted neuroinflammation through TLR-4 via the activation of Jun N-terminal kinase (JNK) and p38 mitogen-activated protein kinase (Benomar et al. 2013). At the cellular level, the activation of resistin/ TLR4 pathway impairs insulin signaling and increases pro-inflammatory cytokines' expression deregulating intrinsic cellular energy homeostasis. Beside, autophagy is a key mechanism in the maintenance of cellular homeostasis through subcellular organelle degradation (Mizushima et al. 2004). Indeed, autophagy is identified as a non-selective degradation pathway induced when cells are energy deprived. However, autophagy also occurs in non-starved cells by degrading cargo materials as damaged mitochondria, invading pathogens and aggregate-prone proteins for instance those induced by many neurodegenerative diseases. Hence, by eliminating injured and aged mitochondria that constitute an important source of reactive oxygen species. Thus, in contrast with resistin action, autophagy reduces cellular inflammatory responses (De Lavera et al. 2017, Fahy et al. 2017). However, the impact of resistin on neuronal autophagy is unknown. Here, we hypothesize that resistin/ TLR4 signaling pathway could affect neuronal autophagy. Thus, we aimed to (1) determine the impact of resistin/ TLR4 signaling pathway on the expression of autophagy markers in human neuroblastoma cell line SH-SY5Y, (2) decipher the signaling pathways linking resistin to the alteration of autophagy and (3) validate in vivo the direct impact of resistin/TLR4 signaling pathway on autophagy markers using TLR4-knockout mice.

\section{Materials and methods}

\section{Cell culture and stimulation}

SH-SY5Y human neuroblastoma cells were grown in Dulbecco's modified Eagle's medium (Life Technologies) supplemented with $10 \%$ FCS, 2 mmol L-glutamine and $100 \mathrm{U} / \mathrm{mL}$ penicillin. Serum-starved cells were incubated in serum-free Dulbecco's modified Eagle's medium for indicated time. Cells were incubated in serum-free medium for $4 \mathrm{~h}$, and then incubated in the presence or absence of resistin $(200 \mathrm{ng} / \mathrm{mL}$ ) (Abcam) during $2 \mathrm{~h}$. The resistin concentration used is chosen according to our previous work (Benomar et al. 2013). Cells were then washed twice with ice-cold PBS prior to protein or RNA extraction using adequate buffers.

\section{Animal treatment}

Adult male C57BL6J mice (27-32g) and TLR-4-knockout mice (Jackson Laboratories) were treated with resistin or vehicle via intracerebroventricular infusion during 3 days. Briefly, mini-osmotic pumps (model 2002; Alzet, Charles River, L'Arbresle, France) were implanted under ketamine $(150 \mathrm{mg} / \mathrm{kg} ;$ Vibrac, Lyon, France)/xylazine $(5 \mathrm{mg} / \mathrm{kg}$; Rompun; Bayer) anesthesia. Brain infusion cannulas were stereotaxically placed into the lateral brain ventricle. The osmotic pumps were housed in a subcutaneous pocket on the dorsal surface of the animal. The mice were then infused with either vehicle or resistin $(1.2 \mu \mathrm{g} / 12 \mu \mathrm{L} /$ day; pumping rate $0.5 \mu \mathrm{L} / \mathrm{h}$ ) for 3 days. All animals were overnight starved and then were killed $(n=6$, per group). The hypothalami were manually dissected and immediately frozen into liquid nitrogen and conserved at $-80^{\circ} \mathrm{C}$. The quality of the dissection was verified by the measurement of POMC and NPY expression known to be specific to the hypothalamus. All procedures were conducted according to the guidelines of laboratory animal care and were approved by the local government commission for animal research: Ethics Committee for animal experimentation of Paris Center and South \# 59 (France), with authorization \# 91-467.

\section{Western blot analysis}

Protein lysates from SH-SY5Y cells were prepared and analyzed by Western blot. Equal amount of total protein extracts $(30 \mu \mathrm{g})$ were separated in SDS-PAGE, using 10\% gels. Then, protein samples were transferred to PVDF membrane (Millipore). The membranes were blocked with 5\% BSA in Tris-buffered saline containing $0.1 \%$ Tween20 (TBST) for $1 \mathrm{~h}$ at room temperature and then incubated overnight with the primary antibodies at $4^{\circ} \mathrm{C}$. The primary antibodies used according to manufacturers' recommendations and all antibodies were from Cell Signaling Technology: LC3A/B, ATG7, P62, phospho (p)-AKT (ser473), AKT, p-mTOR (ser2448), mTOR, AMPK, p-AMPK, $\beta$-tubulin and TLR4. Blots were then incubated 
with secondary mouse or rabbit antibodies coupled to horseradish peroxidase for $1 \mathrm{~h}$ at room temperature. Chemiluminescence signal was developed using a Western Bright ECL kit (Advansta Ins., CA, USA). The blots were finally scanned using the Carestream Molecular Imaging System 4000MM PRO (Carestream Health Inc., CT, USA). Semi-quantitative analysis of the relative density of the bands in Western blots was performed using Carestream software. The protein expression levels were normalized to $\beta$-tubulin expression.

\section{Autophagic flux measurement: LC3II turnover assay}

The LC3II turnover assay measures the amount of LC3II delivered to the lysosomes by comparing the LC3II amounts in the presence and absence of the lysosomal inhibitor $\mathrm{NH}_{4} \mathrm{Cl}(10 \mathrm{mM})$ (MERK, Darmstadt, Germany). Autophagic flux, expressed as 'LC3II net flux', was determined by subtracting the densitometric value of LC3II amount in samples non-treated with lysosomal inhibitor (LC3II $-\mathrm{NH}_{4} \mathrm{Cl}$ ) from the corresponding sample treated with lysosomal inhibitor (LC3II $+\mathrm{NH}_{4} \mathrm{Cl}$ ). This calculation was performed for each experimental condition tested. For each independent experiment, results were expressed as percentage of control.

\section{RNA extraction and quantitative real-time RT-PCR}

Total RNA was extracted from cells using TRIzol reagent according to manufacturer's instructions (Life Technologies). RNA concentration and purity were measured using a NanoDrop ND1000 spectrophotometer (ThermoFisher Scientific). RNA $(0.5 \mu \mathrm{g})$ was subjected to reverse transcriptase and then to quantitative PCR analysis using specific primer pairs that target LC3A (sense 5'GCTGAACCCCACGCA3', antisense 5'GTCCTCGTCTTTCTCCTGCT3'), LC3B (sense 5'AGCATCCAACCAAAATCCCG3'; antisense $\quad 5^{\prime}$ TCACCAACAGGAAGAAGGC3'), ATG7 (sense 5' TTGATGGGTTGGGGCGTG3', antisense 5'TCACAGGATTGGAGTAGGAGAT3'), Beclin-1 (sense 5' CCCGTGGAATGGAATGAGAT3', antisense $5^{\prime}$ CCCGTGGAATGGAATGAGAT3'), TLR4 (sense 5'GACTTGCGGGTTCTACATCA3', antisense $5^{\prime}$ CATAGGGTTCAGGGACAGGT3'), IL6 (sense 5' TCCTCCTGGTGTTGCCTGCT3'; antisense 5'TGAGTGGCTGTCTGTCTGGGG3'), TNF $\alpha \quad$ (5'GCTCCAGGCGGTGCCTTGTTC3'; antisense $\quad 5^{\prime}$ AGGCTTGTCACTCGGGGTTC3'), $\quad \beta$-actin (sense 5'ATCGTGCGTGACATTAAGGAGAAG3', antisense 5' AGGAAGGAAGGCTGGAAGAGTG3'). The PCR is performed in the Step One apparatus (Applied Biosystems), using Fast SYBR Green Master Mix (Ozyme, Saint-Quentin-en-Yvelinne, France). A ratio of specific mRNA/ $\beta$-actin mRNA amplification was calculated to normalize the expression levels.

\section{Immunofluorescence microscopy}

SH-SY5Y cells were washed three times with PBS and then fixed with $4 \%$ paraformaldehyde for $15 \mathrm{~min}$. Cells were permeabilized and blocked with $0.1 \%$ trixon- 100 , $0.2 \%$ fish gelatin and $2 \%$ donkey serum for $1 \mathrm{~h}$. Cells were incubated with primary antibody anti-LC3 (1:100; Cell Signaling Technology) overnight at $4^{\circ} \mathrm{C}$. Cells were then washed in PBS and incubated for one hour at room temperature with secondary antibody Alexa-Fluor 488 (1:500; Life Technologies). The nuclei were stained with DAPI (4',6-diamidino-2-phenylindole) (1:3000, Thermo,). Cells were analyzed on a ZEISS LSM 880 Confocal Laser Scanning Microscope with Zen software. The procedure was performed for three independent cell culture preparations. Quantification of LC3 puncta immunereactivity per cell was performed ( $>20$ cells per group) and imaging procedures were calculated by ImageJ software (NIH). The results were expressed as the relative amount compared with control.

For hypothalamic immunofluorescence, brains were subjected to fixation-infusion with $4 \%$ paraformaldehyde/ PBS. The frozen sections in the coronal plane through the mouse hypothalamus were processed for LC3 (autophagy marker) and NeuN (neuronal marker) immunoreactivities using standard immunohistochemical procedures. Briefly, sections were first incubated with $50 \mathrm{mM} \mathrm{NH}_{4} \mathrm{Cl}$ for $20 \mathrm{~min}$ and were blocked/permeabilized with a solution containing $0.1 \%$ Triton $\mathrm{X}-100,0.2 \%$ fish gelatin, $2 \%$ normal donkey serum for $1 \mathrm{~h}$ at room temperature. Then, sections were incubated overnight at $4^{\circ} \mathrm{C}$ with rabbit anti-LC3 (1:100; Cell Signaling Technology) and mouse anti-NeuN (1:1000; Millipore) antibodies. Immunofluorescence was performed with a combination of Alexa-Fluor 488- or Alexa-Fluor 568-labeled antimouse or anti-rabbit (1:400; Life Technologies) and DAPI (Sigma-Aldrich) in order to identify cell nuclei. Images were captured on a Zeiss LSM-700 confocal microscope. Quantification was performed in a blinded fashion on anatomically matched brain regions identified in $\times 20$ images. Both sides of bilateral structures of the ARC were 
counted on three slides per animal, and replicate values from each animal were individually averaged. For LC3 immunofluorescence, cell puncta were counted manually within pre-specified regions of interest using ImageJ.

\section{Gene silencing using siRNA}

A pool of specific siRNA duplexes targeting human TLR4 gene and non-targeting siRNA (sicontrol) were purchased from ThermoFisher Scientific. Transfection of TLR4 and control siRNA into SH-SY5Y cells was performed using Lipofectamine 2000 (Life Technologies) transfection reagent according to the manufacturer's guidelines. Downregulation of the TLR4 protein synthesis and TLR4 mRNA following siRNA transfection was evidenced by Western blot analysis and real-time RT-PCR.

\section{Data analysis and statistics}

Statistical analysis was performed using ANOVA and Fisher post hoc test (SPSS 16.0 software) to detect significant intergroup differences. Data are presented as mean \pm S.D., and a $P$ value $<0.05$ was considered statistically significant.

\section{Results}

Impact of serum starvation on autophagy markers in SH-SY5Y human neuroblastoma cells

To determine the impact of serum starvation on autophagy, SH-SY5Y human neuroblastoma cells were serum-starved at the indicated times and then incubated with or without serum for $30 \mathrm{~min}$ (RF). The expression levels of autophagy markers were quantified by Western blot and qRT-PCR. The serum starvation for $4 \mathrm{~h}$ significantly increased the protein expression levels of the microtubule-associated protein 1 light chain 3 (LC3-I and LC3-II), known as components of the autophagic vacuole membranes, and then LC3I/LC3II expression returned to the basal level, measured in cells maintained with serum, after $16 \mathrm{~h}$ of starvation (Fig. 1A and B) The serum starvation-induced LC3II/LC3I overexpression was abolished after $30 \mathrm{~min}$ of serum addition (cell re-feeding) (RF) (Fig. 1A and B). We have also shown that serum starvation increased expression of both variants of LC3 gene LC3A and LC3B. One-hour serum starvation significantly increased LC3A expression (Fig. 1F). This augmentation was maintained during $16 \mathrm{~h}$ of starvation with a peak at $4 \mathrm{~h}$. The addition of serum did reduce LC3A expression in cells serum-starved for $4 \mathrm{~h}$ or $16 \mathrm{~h}$ but in those
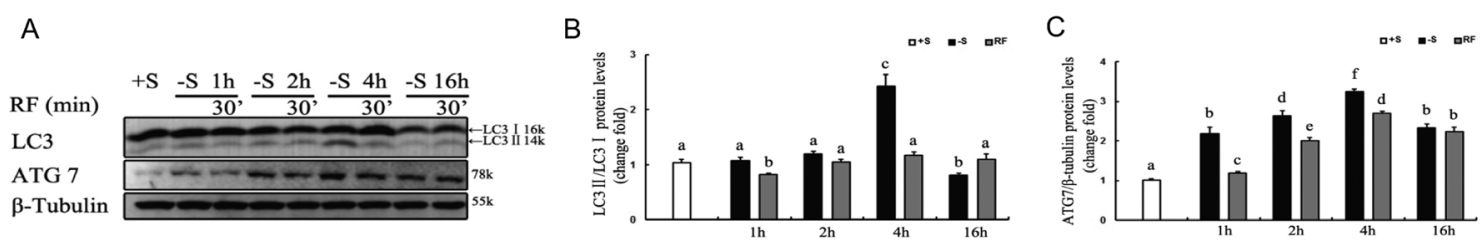

D
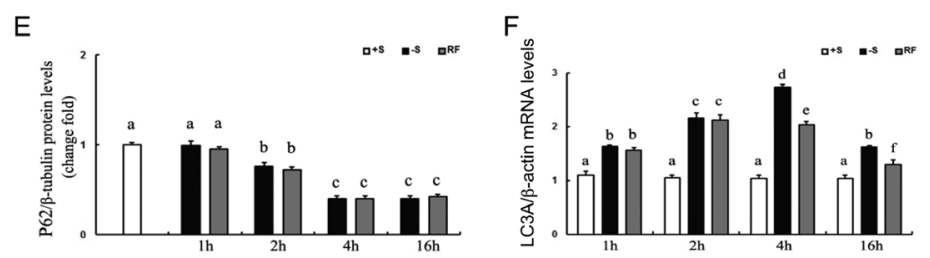

G

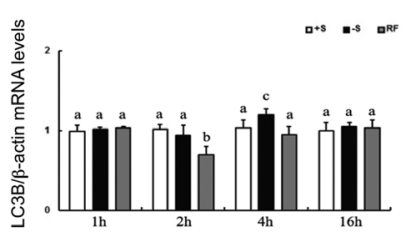

$\mathrm{H}$
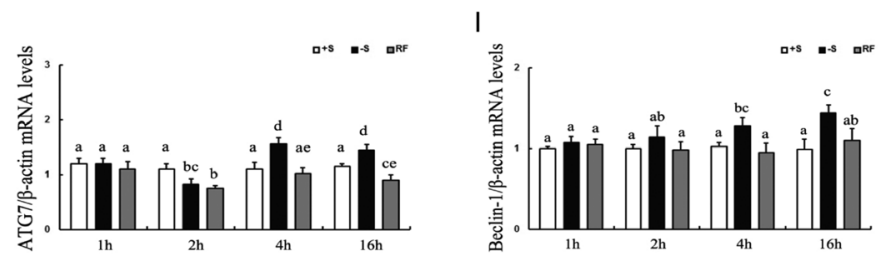

Figure 1

Serum starvation increases autophagy in human neuroblastoma SH-SY5Y cells. SH-SY5Y cells were incubated with serum (+S) or without serum (-S) for indicated time or refed (RF) for $30 \mathrm{~min}$. Western blot analyses were performed using anti-LC3 or anti-ATG7 (A) or anti-p62 (D) or $\beta$-tubilin (A). The results are expressed as ratio of LC3 II/LC3 I (B), ATG7/ $\beta$-tubulin (C) or p62/ $\beta$-tubulin (E). In parallel, total mRNA were prepared from cells and subjected to qRT-PCR using adequate primers in order to measure the expression levels of LC3A (F), LC3B (G), ATG7 (H) or Beclin (I). The results were normalized to $\beta$-actin. All the results are expressed as means \pm s.D. ( $n=3 /$ group). Different letters indicate significant differences with $P<0.05$. Each blot for LC3, ATG7, p62 or $\beta$-tubilin is part of the same gel without any division or insertion. 
starved for 1 or $2 \mathrm{~h}$ Fig. 1F). LC3B expression was less affected by serum starvation, except after $4 \mathrm{~h}$ where its expression exhibited a significant augmentation (Fig. 1G). We have also measured the expression ATG7, autophagy-related 7 that encodes an E1-like-activating enzyme essential for autophagy initiation and vacuole formation. ATG7 protein expression was increased in response to serum starvation since the first hour, and this augmentation was maintained during 16 hours of starvation (Fig. 1A and C). The addition of serum after 1,2 or $4 \mathrm{~h}$ of starvation significantly reduced ATG7 expression (Fig. 1C). At the mRNA level, ATG7 expression was augmented after 4 and 16 hours of starvation and declined after $2 \mathrm{~h}$ (Fig. $1 \mathrm{H}$ ). Furthermore, we measured the expression of Beclin-1, which is involved in the initiation of autophagosome formation. We showed that 4- and 16-h serum starvation increased its expression that was abolished by the addition of serum (Fig. 1I). Finally, we measured the expression of p62 known as the specific autophagic substrate that declines when autophagy is activated. We showed that serum deprivation for 2, 4 and $16 \mathrm{~h}$ significantly reduced p62 expression and the addition of serum for $30 \mathrm{~min}$ was not able to restore the basal level of p62 expression (Fig. 1D and E).

\section{Resistin reduces the starvation-induced autophagy and increases inflammation}

To investigate the effect of resistin on autophagy, SH-SY5Y cells were serum starved for various periods of time in the presence or absence of resistin. Resistin significantly reduced LC3-II/LC3I ratio induced by 2 or $4 \mathrm{~h}$ of starvation (Fig. 2A and B). Resistin treatment decreased LC3A expression induced by 1,4 or $16 \mathrm{~h}$ of serum starvation (Fig. 2F). LC3B expression was less affected by resistin treatment, except after 1 or $4 \mathrm{~h}$ of starvation (Fig. 2G). Resistin also significantly reduced ATG7 expression at the protein and mRNA levels since $1 \mathrm{~h}$ of serum starvation till 16h (Fig. 2A, C and H). Furthermore, the cell exposure to resistin diminished the expression of Beclin- 1 after $4 \mathrm{~h}$ of serum starvation (Fig. 2I). The serum starvation also downregulated p62 from 1 to $16 \mathrm{~h}$ (Fig. 2D and E) and resistin treatment transiently recovered p62 expression in cells starved for 1 or $2 \mathrm{~h}$ (Fig. 2D and E). Furthermore, following $4 \mathrm{~h}$ of resistin treatment, serum-starved cells exhibited a higher expression of pro-inflammatory markers IL6 and TNF $\alpha$ as compared to control cells (Fig. 2J).
A

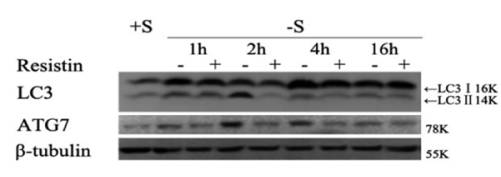

D
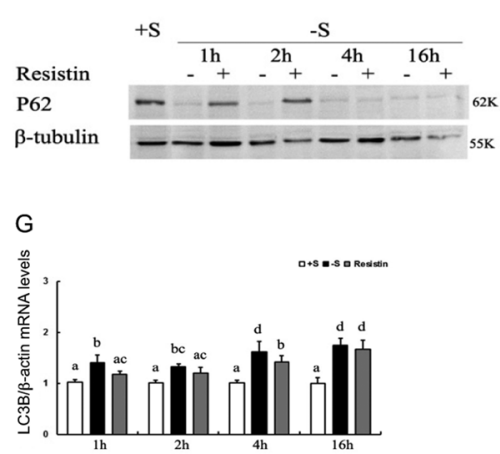

B

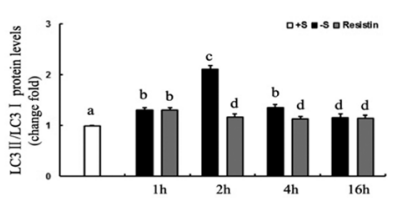

E

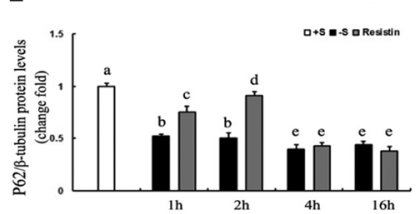

$\mathrm{H}$

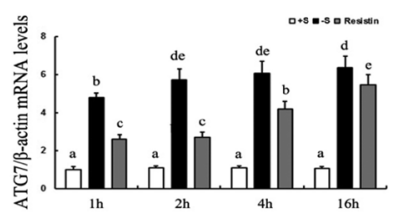

C
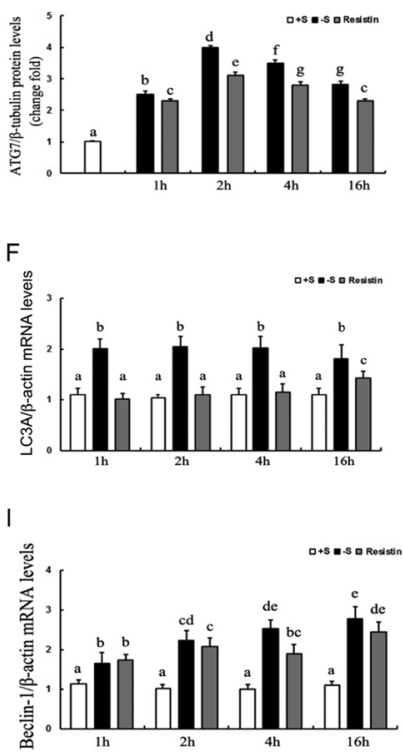

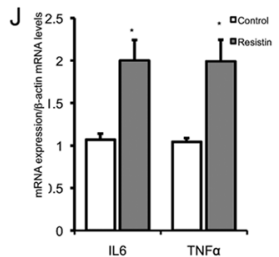

Figure 2

Resistin reduces autophagy and increases inflammation in SH-SY5Y cells. Cells were serum-starved during $4 \mathrm{~h}$ and then incubated with resistin (200 ng/ $\mathrm{mL})(\mathrm{R})$ or without resistin $(-S)$ for 1, 2, 4 and $16 \mathrm{~h}$. Control cells were maintained in the presence of serum (+S). Western blot analyses were performed using anti-LC3 and anti-ATG7 (A), P62 (D). The proteins on the blots were revealed by ECL and bands were quantified by densitometry. The results are

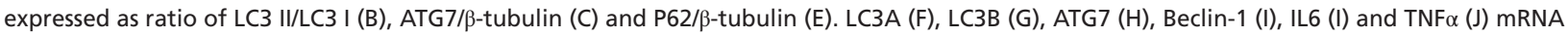
expression levels were measured by real-time RT-PCR. All the results are expressed as means \pm s.D. ( $n=3 /$ group). Different letters indicate significant differences with $P<0.05$. For IL6 and TNF $\alpha$ * indicates $P<0.05$ when comparing control cells to cells treated with resistin. Each blot for LC3, ATG7, p62 or $\beta$-tubilin is part of the same gel without any division or insertion. 
A

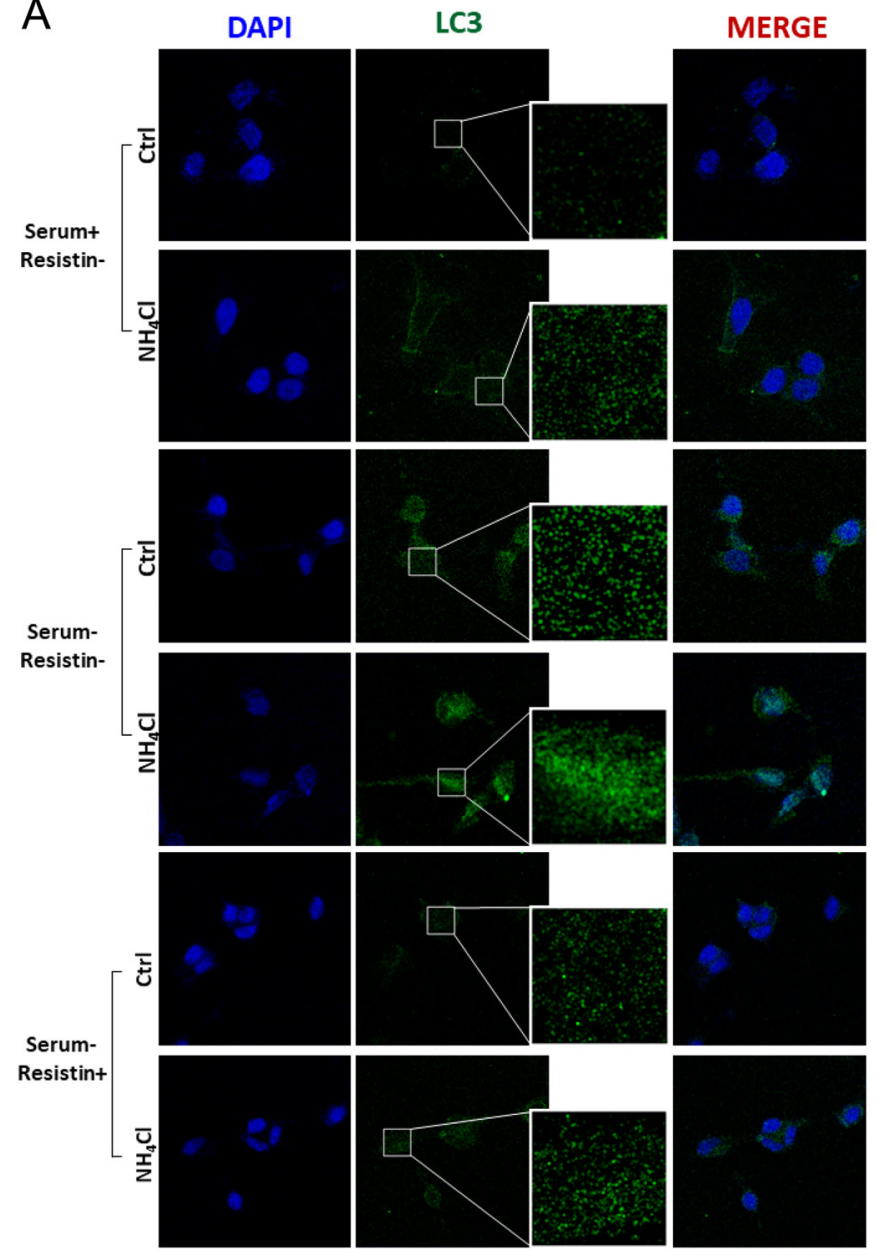

B

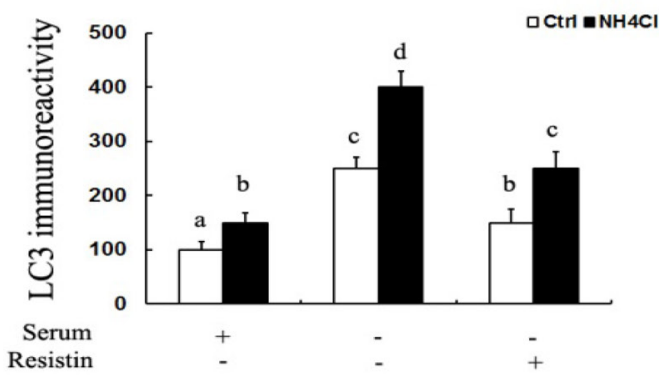

C

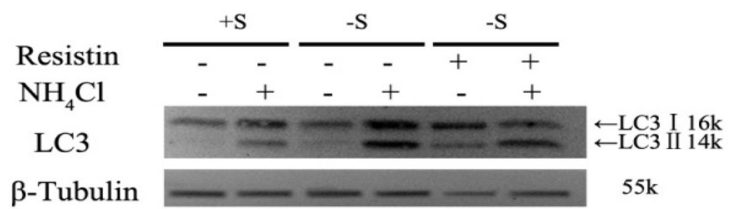

口+S घ-S 口Resistin

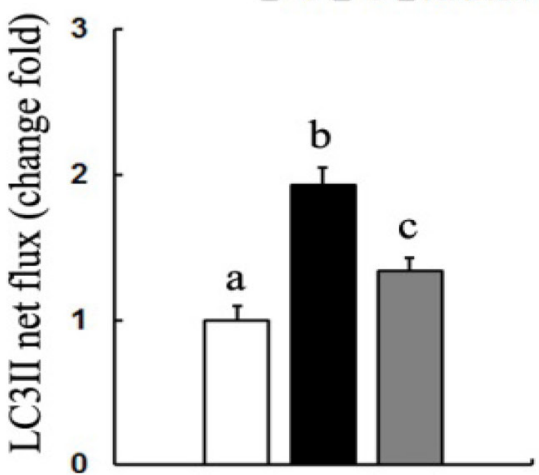

Figure 3

Resistin reduces LC3II net flux. (A) LC3 expression was assessed by immunocytochemistry assay. SH-SY5Y was labeled for LC3 using anti-LC3 antibodies (green) and DAPI (blue, nuclei). Figures are representative of three independent experiments $(\mathrm{bar}=20 \mu \mathrm{m})$. Cells were pretreated with inhibitor $\mathrm{NH}_{4} \mathrm{Cl}$ $(10 \mathrm{mM})$ (an inhibitor of lysosomal degradation) or without $\mathrm{NH}_{4} \mathrm{Cl}$ for $1 \mathrm{~h}$ in the presence or not of resistin. (B) Quantification of the number of $\mathrm{LC} 3$ puncta immunoreactivity (green) per cell in each condition (>20 cells per group). All data are means \pm S.D. ( $n=3-6 /$ group). (C) Protein lysates of SH-SY5Y

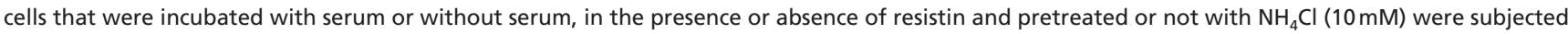
to Western blot using anti-LC3 antibodies and normalized to $\beta$-tubilin. (D) Values of LC3II net flux were determined by substracting the densitometric values of $\mathrm{LC} 3 \mathrm{Il}$ amount in $\mathrm{NH}_{4} \mathrm{CL}$ untreated cells from the corresponding cells treated with $\mathrm{NH}_{4} \mathrm{Cl}$. All the results are expressed as means \pm s.D. ( $n=3-6 /$ group). $a, b, c, d$, eDenote significant difference at $P<0.05$ by ANOVA and Fisher post hoc test. Each blot for LC3 or $\beta$-tubilin is part of the same gel without any division or insertion.

\section{Resistin inhibits autophagic flux}

To further investigate the inhibition of autophagy by resistin, we have measured LC3 expression levels in the absence or presence of $\mathrm{NH}_{4} \mathrm{Cl}$, an inhibitor of autophagosomal degradation. Indeed, LC3 is degraded at the final stages of autophagy, and in the presence of $\mathrm{NH}_{4} \mathrm{Cl}$, LC3 is accumulated as evidenced by LC3 puncta immunoreactivity in serum-starved cells as compared to non-starved cells (Fig. 3A). Despite the presence of $\mathrm{NH}_{4} \mathrm{Cl}$, resistin significantly diminished the LC3 accumulation (Fig. 3A and B). We next determined autophagic flux by the LC3II turnover through the measurement of LC3-II delivered to the lysosomes by comparing the LC3-II amounts in the presence and absence $\mathrm{NH}_{4} \mathrm{Cl}$ (LC3-II net flux). We found that resistin reduced starvation-induced LC3-II net flux in SH-SY5Y cells (Fig. 3C and D).

\section{Resistin acts on signaling pathways implicated in serum starvation-induced autophagy}

To investigate the possible mechanisms underlying the resistin-dependent inhibition of autophagy, we examined AMPK-mTOR pathways. Indeed, AMPK is known as an inducer of autophagy through different mechanisms 
A

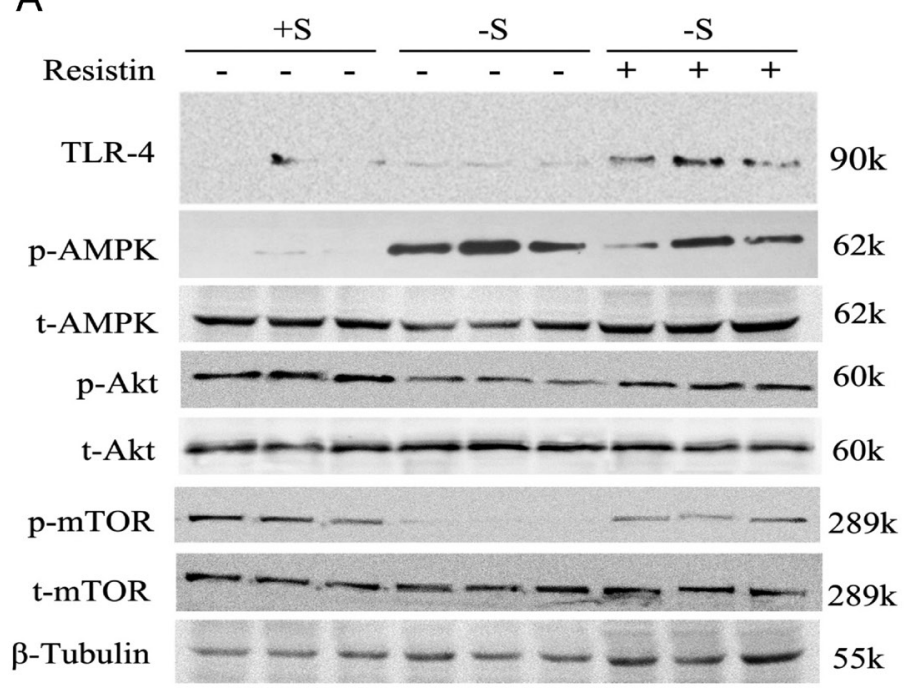

B
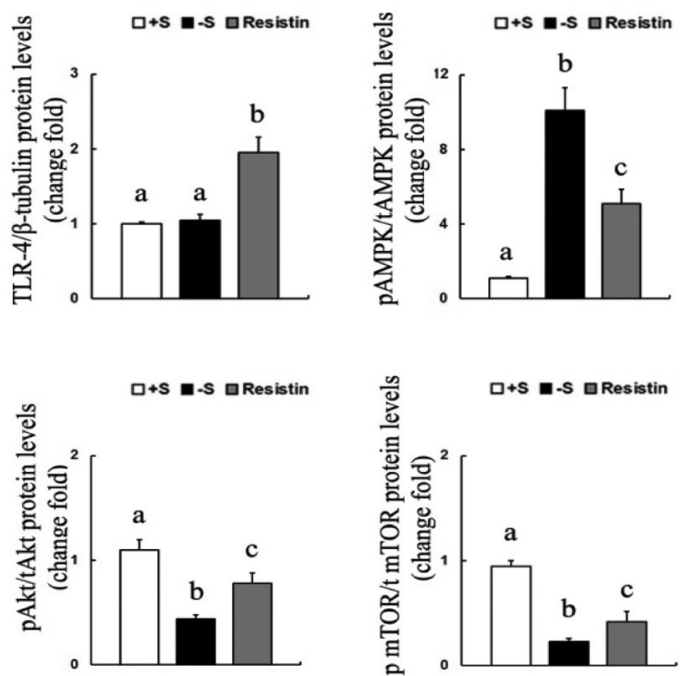

Figure 4

Resistin inhibits AMPk phosphorylation and activates Akt/mTOR pathway. SH-SY5Y cells were incubated in the absence or presence of serum for $4 \mathrm{~h}$ or in the absence of serum and in the presence of resistin $(200 \mathrm{ng} / \mathrm{mL})$ during $2 \mathrm{~h}$. Cell lysates were subjected to Western blot in order to measure AMPK, Akt and mTOR phosphorylation. TLR4 was also measured and all blots were normalized to total proteins and $\beta$-tubulin (panel A). The results were expressed as ratio of $\mathrm{p}$-AMPK/total-AMPK, p-Akt/total-Akt, TLR-4/ $\beta$-tubulin (panel B). Results are expressed as means \pm s.D. ( $n=3 / g$ roup). Different letters indicate significant differences with $P<0.05$. Each blot for TLR4, $\mathrm{p}$-AMPK, t-AMPK, $\mathrm{p}$-Akt, tAkt, $\mathrm{p}$-mTOR, t-mTor or $\beta$-tubilin is part of the same gel without any division or insertion.

including the inhibition of PI3K-mTOR pathway. We have previously shown that resistin binds to TLR4, here we confirmed the upregulation of TLR4 in serum-starved cells treated with resistin (Fig. 4A and B). Our data also showed that resistin decreased AMPK phosphorylation in serumstarved cells (Fig. 4A and B). In contrast, serum deprivation decreased both Akt and mTOR phosphorylation that were recovered by resistin treatment (Fig. $4 \mathrm{~A}$ and B). This suggests that resistin could modulate autophagy process through the inhibition of AMPK phosphorylation and the activation Akt-mTOR signaling pathways.

\section{Resistin inhibits autophagy through TLR4}

We have previously shown that resistin/TLR4 signaling pathway promotes insulin resistance and neuroinflammation (13). In order to investigate whether resistin inhibits autophagy through TLR4, this receptor was silenced in SH-SY5Y cells using siRNA strategy leading to marked downregulation of TLR4 expression at both mRNA and protein levels (Fig. 5A, B and C). Here, we have shown that resistin treatment reduced the starvationinduced upregulation of LC3I (Fig. 5D and E) and LC3II (Fig. 5D and E). LC3A and LC3B mRNA expressions were also inhibited by resistin treatment (Fig. 5I and J). Similar results were found concerning the expression of
ATG7 at both protein and mRNA levels (Fig. 5D, F and $\mathrm{K})$. These effects were abolished in cells expressing siTLR4 (Fig. 5). We have also shown that Beclin-1 expression was slightly, but not significantly, inhibited by resistin and in cells lacking TLR-4, this effect is abolished (Fig. 5L). The starvation-induced downregulation of p62 was partially but significantly diminished by resistin treatment (Fig. 5G and $\mathrm{H}$ ), this effect was strongly decreased in siTLR4 cells (Fig. 5G and H).

To further assess the role of resistin/TLR4 signaling pathway on autophagy, we measured LC3 expression in the presence of $\mathrm{NH}_{4} \mathrm{Cl}$. We have shown that the resistininduced diminution of LC3I and LC3II in the presence of $\mathrm{NH}_{4} \mathrm{Cl}$ was completely abolished in siTLR4 cells (Fig. 6A and B). Furthermore, TLR4 silencing abolished the inhibitory effect of resistin on AMPK phosphorylation (Fig. 6C and D) and the resistin-dependent phosphorylation of Akt and mTOR (Fig. 6C, E and F).

We have also investigated the impact of TLR4 silencing on LC3 expression and accumulation in the presence of $\mathrm{NH}_{4} \mathrm{Cl}$ using immunohistochemistry approach. We confirmed that resistin reduced the accumulation of LC3 in the presence $\mathrm{NH}_{4} \mathrm{Cl}$ in serum-starved cells (Fig. 7A and B). In siTLR4 cells, resistin effect was strongly diminished as evidenced by a higher LC3 accumulation in the presence of $\mathrm{NH}_{4} \mathrm{Cl}$ as compared to control cells (Fig. 7A and B). 
A

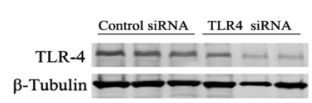

E

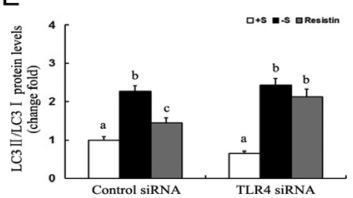

I

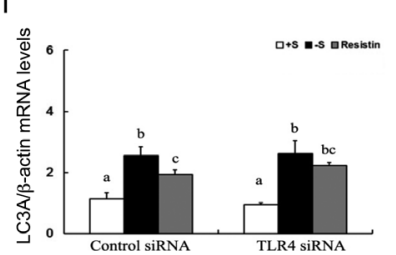

$\mathrm{B}$

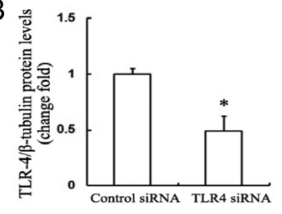

F
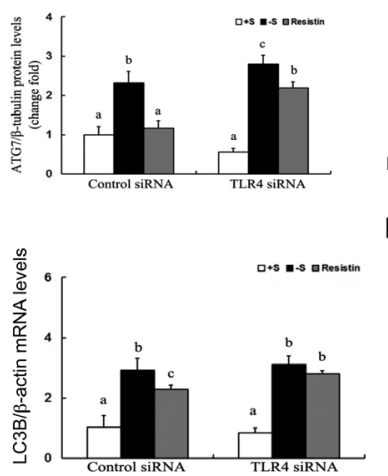

C

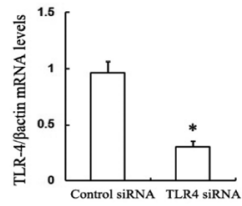

G

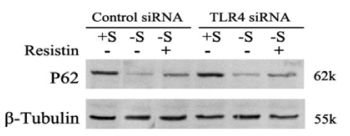

K

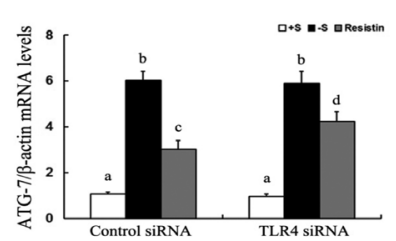

D

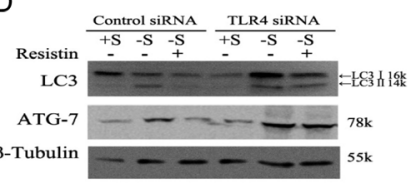

$\mathrm{H}$

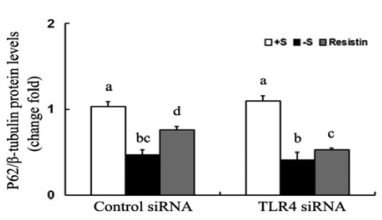

L

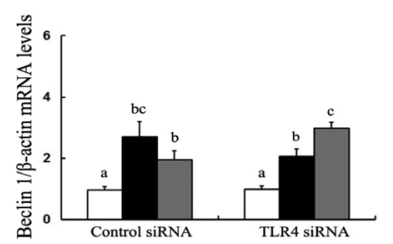

Figure 5

Resistin inhibits autophagy through TLR4. SH-SY5Y cells were treated by control siRNA and specific siRNA duplexes targeting TLR4. (A) Immunoblot of TLR4 in control and siTLR4-treated cells. The results were expressed as the ratio of TLR4/ $\beta$-tubulin $(n=3)$ (B). (C) TLR4 mRNA levels were measured by real-time RT-PCR $(n=3)$ and normalized to $\beta$-actin in cells treated by control siRNA or siTLR4. (D) Immunoblots for LC3 and ATG7 in the presence or absence of serum, and in the presence or absence of resistin $(200 \mathrm{ng} / \mathrm{mL}$ for $2 \mathrm{~h})$ in SH-SY5Y cells treated with control siRNA or TLR4 siRNA ( $n=3)$. The results were expressed as the ratio of LC3II/LC3I (E) and ATG 7/ק-tubulin (F) $(n=3)$. (G) Immunoblots for p62 in the presence or absence of serum, and in the presence or absence of resistin $(200 \mathrm{ng} / \mathrm{mL}$ for $2 \mathrm{~h})$ in SH-SY5Y cells treated with control siRNA or TLR4 siRNA $(n=3)$. The results were expressed as the ratio of p62/ $\beta$-tubulin (H) $(n=3)$. LC3A (I), LC3B (J), ATG $7(\mathrm{~K})$ and Beclin-1 (L) mRNA expression levels were determined by real-time RT-PCR $(n=3)$. The expression levels were normalized to $\beta$-actin. All the results are expressed as means \pm s.D. ( $n=3 /$ group). Different letters indicate significant differences with $P<0.05$. Each blot for TLR4, LC3, ATG7, p62 or $\beta$-tubilin is part of the same gel without any division or insertion.

\section{Resistin inhibits autophagy and increases}

\section{inflammation in the hypothalamus through TLR4}

We next studied in vivo the impact of resistin on autophagy. For this purpose, we measured the expression of autophagy markers in the hypothalamus of WT mice and Tlr4-/- mice in response to resistin treatment. This treatment significantly reduced LC3A, LC3B, ATG7 and Beclin-1 mRNAs expression in WT mice (Fig. 8A, B, C and D). Importantly, resistin effect was completely abolished in the hypothalamus of Tlr4-/- mice (Fig. 8A, B, C and D). Resistin treatment also increased the expression of pro-inflammatory cytokines IL6 and TNF $\alpha$ in the hypothalamus of WT mice but not in Tlr4-/- mice (Fig. 8E and F). To further investigate the impact of resistin on autophagy, we measured the LC3 immunofluorescence in the arcuate nucleus in response to resistin in WT and Tlr4-/- mice. We showed that resistin ICV treatment for 3 days significantly reduced LC3 neuronal immunofluorescence (Fig. 9A and B). Resistin effect on LC3 inmmunofluorescence is completely abolished in Tlr4-/- mice (Fig. 9C and D).

\section{Discussion}

In the current study, we hypothesized that the activation of resistin/TLR4 signaling pathway could compromise autophagy in neuronal cells. Using human neuroblastoma SH-SY5Y cell line, we show that resistin treatment inhibits autophagy and increases inflammation in a TLR4-dependent manner TLR4. We also show that resistin activates Akt and mTOR phosphorylation and reduces that of AMPK. This could constitute the signaling pathways implicated in the resistin-dependent inhibition of autophagy. This study also shows that resistin is able to inhibit autophagy and to increase inflammation in mice hypothalamus through TLR4.

Recent studies associate compromised autophagy with the onset of obesity, insulin resistance and type 2 diabetes (Mizunoe et al. 2017, Moller et al. 2017). These metabolic disorders are characterized by the alteration of energy homeostasis control and low-grade inflammation status. The link between obesity and insulin resistance has been recognized for decades as reported in recent findings (Kahn \& Flier 2000, Wellen \& Hotamisligil 2003, 
A

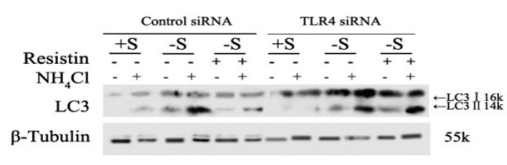

D

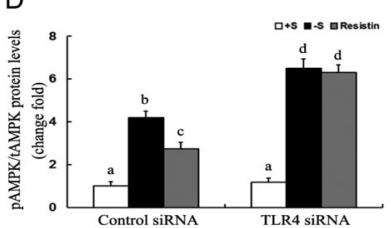

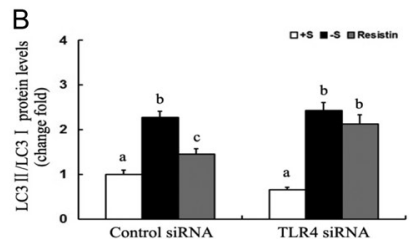

E

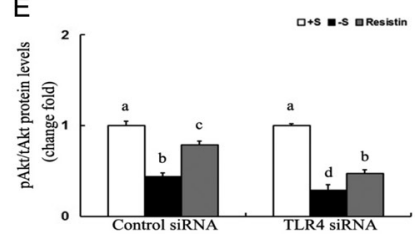

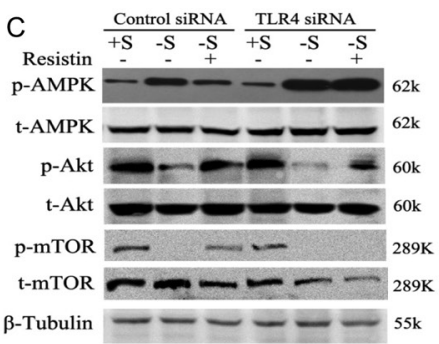

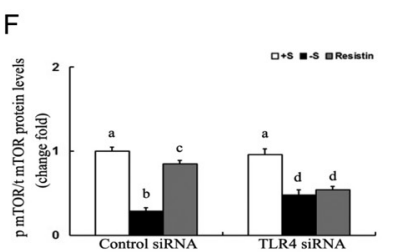

Figure 6

Resistin inhibits LC3II net flux and AMPK through TLR4. Immunoblots of LC3 in the presence of serum, or absence of serum or resistin (200 $\mathrm{ng} / \mathrm{mL}$ for $2 \mathrm{~h}$ ) treated with or without $\mathrm{NH}_{4} \mathrm{Cl}$ lysosomal inhibitor in SH-SY5Y cells transfected by control siRNA or TLR4 siRNA (A). LC3 flux were determined by subtracting LC3-II densitometric value of $\mathrm{NH}_{4} \mathrm{CL}$-untreated cells from corresponding cells treated with $\mathrm{NH}_{4} \mathrm{Cl}(\mathrm{B})(n=3)$. Panel $\mathrm{C}$ shows immunoblots of phosphorylated AMPK, mTOR and Akt in the presence of serum, or absence of serum or resistin ( $200 \mathrm{ng} / \mathrm{mL}$ for $2 \mathrm{~h}$ ) in SH-SY5Y cells treated with control siRNA or TLR4 siRNA. The results were expressed as ratio of p-AMPK/t-AMPK (D), p-Akt/t-Akt (E) and pmTOR/mTOR (F), the protein load control is assessed by $\beta$-tubilin (C) $(n=3)$. All the results are expressed as means \pm s.D. ( $n=3 /$ group). Different letters denote significant differences at $P<0.05$ by ANOVA and Fisher post hoc test. Each blot for LC3, p-AMPK, t-AMPK, p-Akt, t-Akt, p-mTOR, t-mTOR or $\beta$-tubilin is part of the same gel without any division or insertion.

Benomar et al. 2016). In this context, inflammation is a common feature of obesity, insulin resistance and type 2 diabetes. Beside the deleterious effect of inflammation on peripheral tissues, its impact at the neuronal level especially in the hypothalamus is now recognized as a strong promoter of overall insulin resistance and inflammation (Thaler \& Schwartz 2010, Cai \& Lin 2011). Recent studies reported a novel mechanism linking neuroinflammation to whole-body insulin resistance onset orchestrated by resistin, an adipokine, which acts through the activation of hypothalamic TLR4 signaling pathway (Benomar et al. 2013, 2016). This promotes both hypothalamic and peripheral inflammation leading to the alteration of insulin, adiponectin and FGF21 signaling (Benomar et al. 2016). Furthermore, it has been reported that neuroinflammation impairs autophagy (Bosch \& Kichian 2015, Su et al. 2016, Yerra \& Kumar 2017), but the impact of resistin on autophagy was not yet investigated and remains unknown. Here, we used human neuroblastoma SH-SY5Y cell line as model to decipher the mechanism by which resistin could potentially affect neuronal autophagy. We firstly showed that serum starvation increases autophagy as evidenced by the higher expression of autophagy markers. This is in good agreement with previously published data showing that cell energy restriction increased autophagy to fulfill cell energy needs (Yang et al. 2016). We show that resistin inhibits starvation-induced autophagy, and this effect is exacerbated in the presence of $\mathrm{NH}_{4} \mathrm{Cl}$, an inhibitor of autophagosomal degradation. Thus, resistin strongly diminished LC3II net flux. This is the first study demonstrating the role of resistin in the inhibition of neuronal autophagy. Thus, besides its deleterious effects such neuroinflammation and the alteration of both insulin and adiponectin signaling at the neuronal level (Benomar et al. 2013, 2016), resistin inhibits neuronal autophagy, which is considered as a neuronal protective mechanism during fasting conditions or nutrient deprivation ( $\mathrm{Du}$ et al. 2009, Alirezaci et al. 2010). Furthermore, we decipher the signaling pathways involved in resistin action and demonstrate that resistin reduced the starvationinduced AMPK phosphorylation. Indeed, this is in good agreement with previous reports demonstrating that AMPK phosphorylation promotes autophagy in the hypothalamus and increases NPY and decreases POMC expressions (Oh et al. 2016). Resistin treatment also increased mTOR and Akt phosphorylation contributing most likely to the inhibition of neuronal autophagy. This finding corroborates with previous reports where the inhibition of mTOR promoted autophagy (Lee et al. 2010, Alers et al. 2012). Interestingly, our findings show that resistin increased the expression of TLR4, the binding site for resistin (Benomar et al. 2013); this may further potentiate the resistin-induced inhibition of neuronal 
A

Control SiRNA

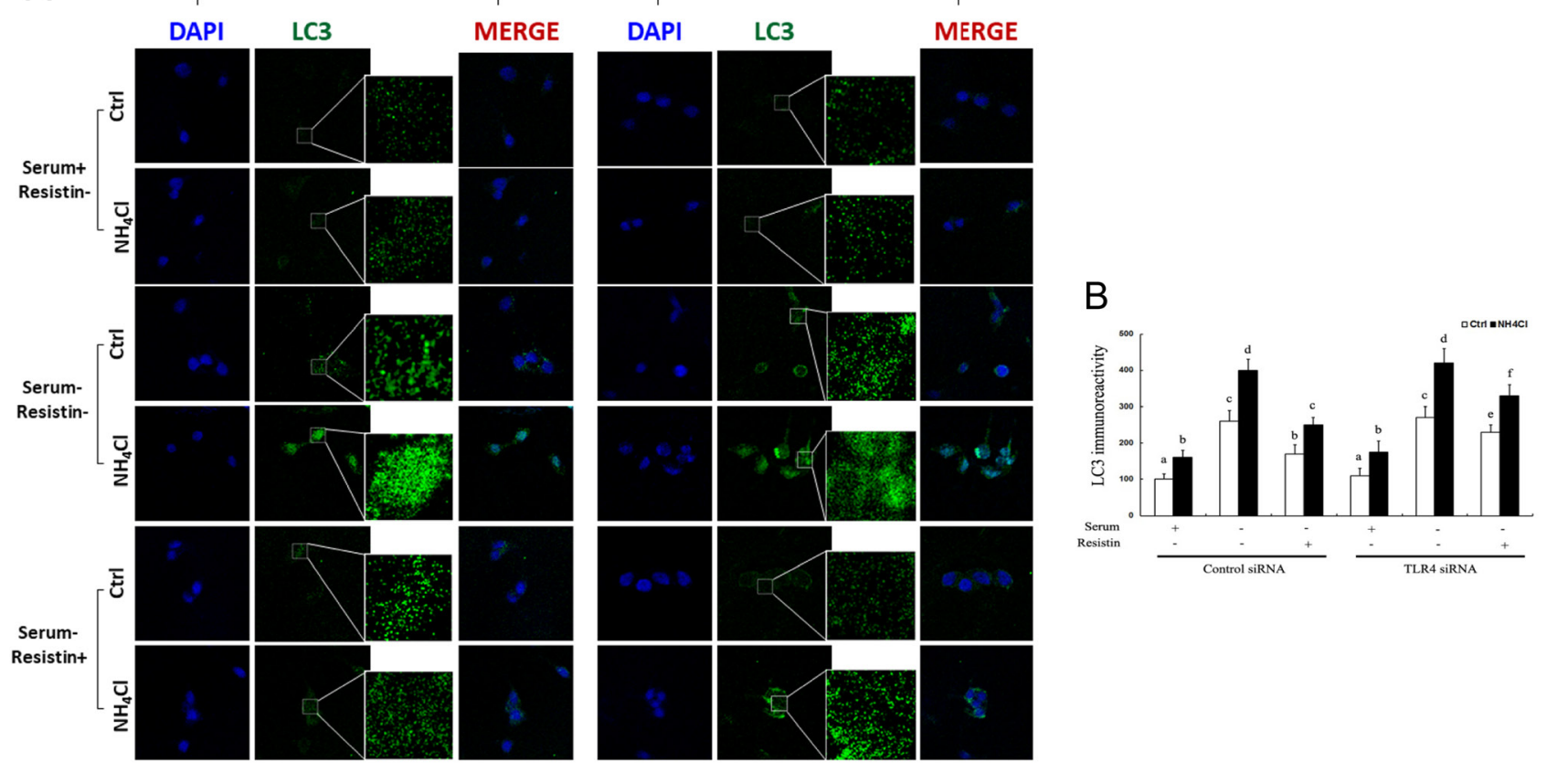

Figure 7

The immunohistochemical distribution of LC3 is inhibited by resistin in TLR4-dependent manner even in the presence of $\mathrm{NH}_{4} \mathrm{Cl}$. (A) $\mathrm{LC} 3$ distribution was assessed by immunocytochemistry assay. SH-SY5Y was labeled for LC3 using anti-LC3 antibodies (green) and DAPI (blue, nuclei). Figures are representative of three independent experiments ( $\mathrm{bar}=20 \mu \mathrm{m})$. siControl or siTLR4 Cells were pretreated with inhibitor $\mathrm{NH}_{4} \mathrm{Cl}(10 \mathrm{mM})(\mathrm{an}$ inhibitor of lysosomal degradation) or without $\mathrm{NH}_{4} \mathrm{Cl}$ for $1 \mathrm{~h}$ in the presence or not of resistin. (B) Quantification of the number of LC3 puncta immunoreactivity (green) per cell in each condition ( $>20$ cells per group). All data are means \pm s.D. $(n=3-6 /$ group). Different letters indicate a significant difference with $P<0.05$.

autophagy. This is further evidenced in si-TLR4 neuronal cells where resistin was unable to diminish or increase AMPK or mTOR/Akt phosphorylation, respectively. It is noteworthy to indicate that resistin is able to inhibit autophagy markers at the mRNA levels; however, the underlying mechanisms are unknown. Taken together, these data indicate that resistin compromises neuronal autophagy through TLR4. Importantly, this finding was
A

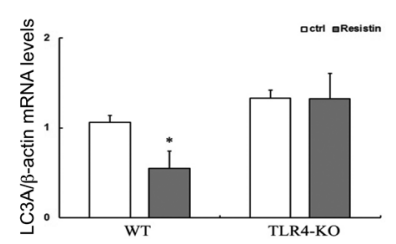

$\mathrm{E}$

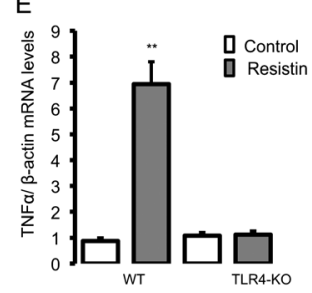

B
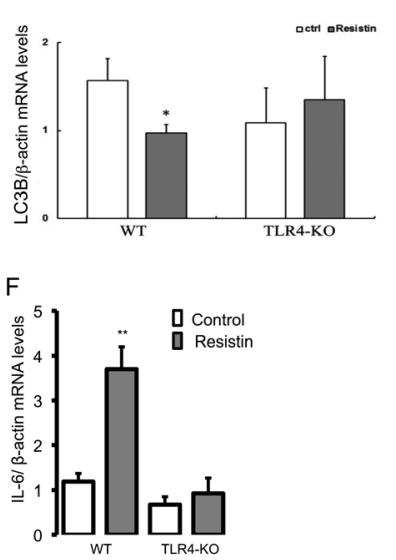

C

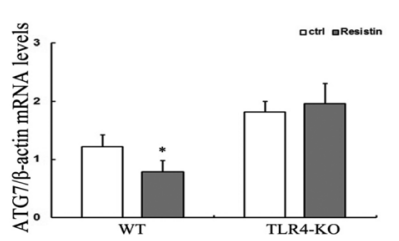

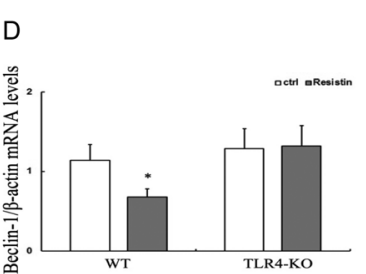

Figure 8

Resistin/TLR4 pathway decreases autophagy and increases inflammation in mice hypothalamus. Male WT C57BL mice or TLR-4-knockout mice were treated through ICV route by resistin $(1.2 \mu \mathrm{g} / \mathrm{day})$ or placebo for 3 days. At the end of the infusion period, the animals were killed. LC3I (A), LC3II (B), ATG7 (C), Beclin-1 (D), TNF $\alpha$ (E) and IL6 (F) mRNA were measured by real-time RT-PCR in hypothalamus of mice. Results were normalized to $\beta$-actin. All data are expressed as means \pm S.D. ( $n=3-6 /$ group). * and ** indicate respectively $P<0.05$ and $P<0.005$ when comparing control to resistin treatment.

๑) 2018 Society for Endocrinology Published by Bioscientifica Ltd. Printed in Great Britain 
Wt mice 3-days ICV saline

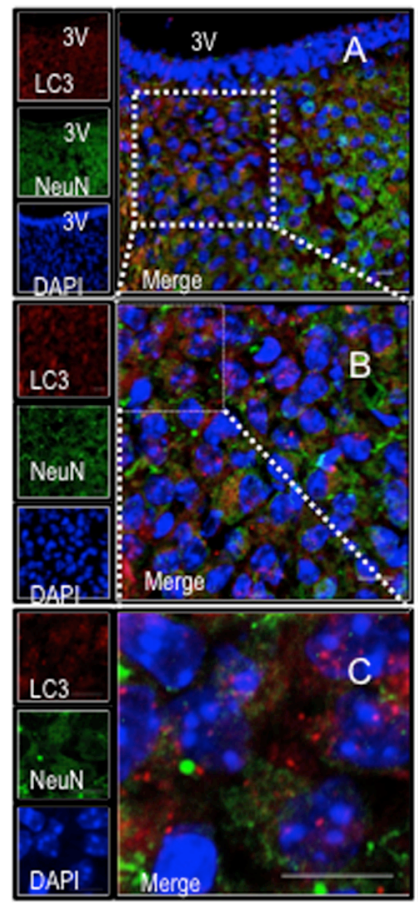

Wt mice 3-days ICV resistin
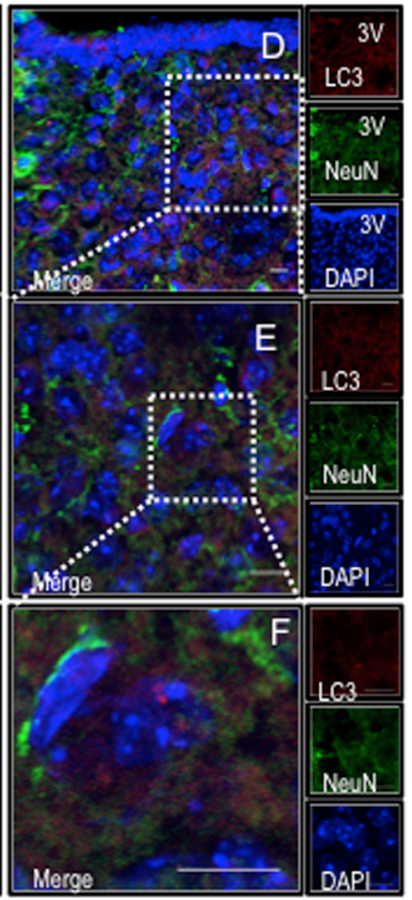

TLR4-/- mice 3-days ICV saline

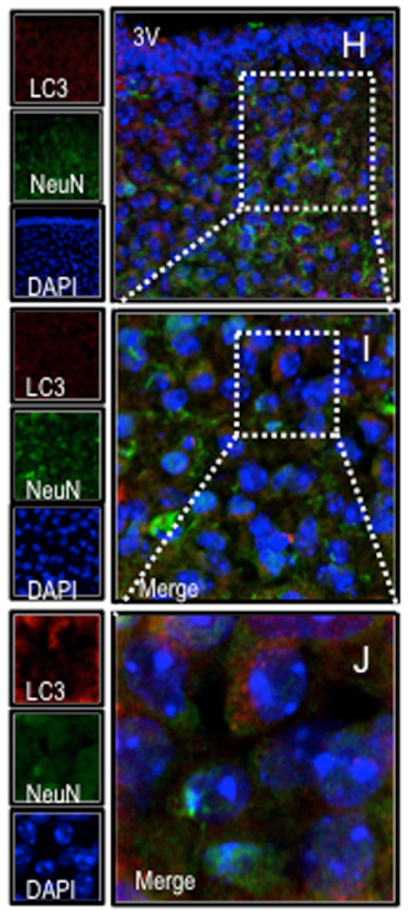

TLR4-/- mice 3-days ICV resistin

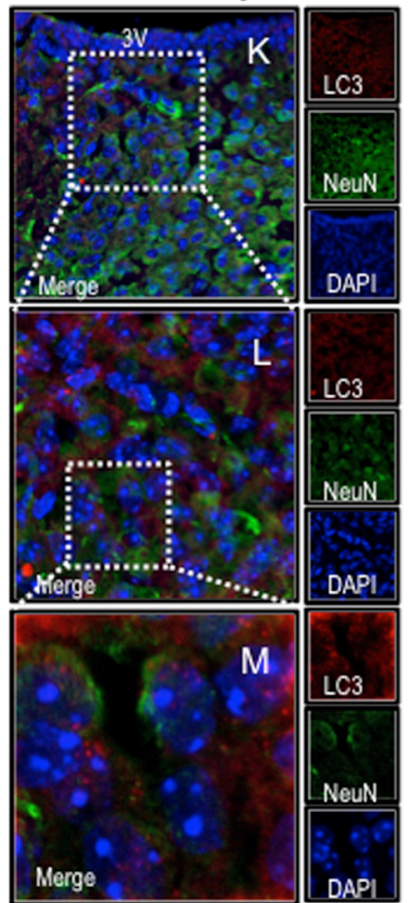

G

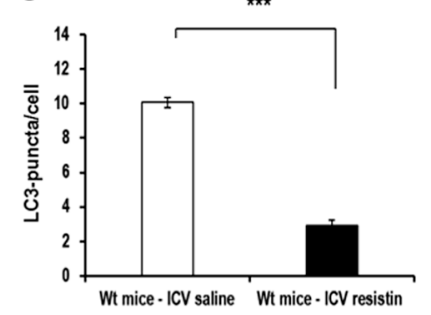

$\mathrm{N}$

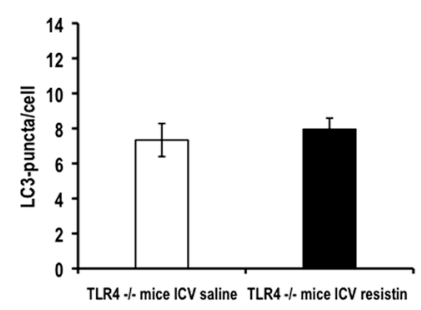

Figure 9

Resistin/TLR4 pathway decreases hypothalamic neuronal LC3 immunofluorescence. Immunofluorescence detection of LC3 protein (autophagy marker) and NeuN (neuronal marker) was performed in coronal sections of hypothalamus $(20 \mu \mathrm{m})$ from mice $(n=2)$ that have received 3 -day ICV resistin infusion $(1.2 \mu \mathrm{g} /$ day/mice) or saline. WT or TLR-I- mice were used. (A, B and C) LC3 and NeuN staining throughout the ARC of Wt mice that received 3-day ICV of saline. (D, E and F) LC3 and NeuN staining of Wt mice ARC that received 3-day ICV of resistin. (A) Low-magnification view (original magnification ( $\times 40)$ ). The dashed box represents the view in B. (B) Higher-magnification view (zoom $\times 2$, original magnification ( $\times 40)$ ). The dashed box represents the view in C. (C) Higher-magnification view (zoom $\times 6$, original magnification $(\times 40)$ ). (D) Low-magnification view (original magnification ( $\times 40)$ ). The dashed box represents the view in E. (E) Higher-magnification view (zoom $\times 2$, original magnification $(\times 40)$ ). The dashed box represents the view in F. (F) Highermagnification view (zoom $\times 6$, original magnification $(\times 40)$ ). Scale bar $10 \mu \mathrm{m}, 3 \mathrm{~V}$ third ventricle. (G) Quantification of the number of LC3 puncta immunoreactivity (red) per cell in each condition ( $>20$ cells per group). All data are means \pm S.D. $* * *$ indicates $P<0.01$. (H, I and J) LC3 and NeuN staining throughout the ARC of KO TLR4 mice that received 3-day ICV of saline. (K, L and M) LC3 and NeuN staining throughout the ARC of KO TLR4 mice that received 3-day ICV of resistin. (H) Low-magnification view (original magnification $(\times 40)$. The dashed box represents the view in I. (I) Higher-magnification view (zoom $\times 2$, original magnification $(\times 40)$ ). The dashed box represents the view in J. (J) Higher-magnification view $($ zoom $\times 6$, original magnification $(\times 40)$ ). (K) Low-magnification view (original magnification $(\times 40)$. The dashed box represents the view in $\mathrm{K}$. (K) Higher-magnification view $($ zoom $\times 2$, original magnification $(\times 40)$ ). The dashed box represents the view in M. (M) Higher-magnification view (zoom $\times 6$, original magnification $(\times 40)$ ). Scale bar $10 \mu \mathrm{m}, 3 \mathrm{~V}$ third ventricle. (N) Quantification of the number of LC3 puncta immunoreactivity (red) per cell in each condition (>20 cells per group).

confirmed in vivo using mice lacking TLR4, where the resistin-dependent inhibition of autophagy is completely abolished. We have chosen the ICV route for resistin because we aimed to investigate the role of central resistin on hypothalamic autophagy to validate data obtained in cell model. Indeed, resistin intravenous or intraperitoneal treatment might implicate other peripheral components (for instance, inflammatory cytokines) and thus the direct effect of resistin on hypothalamic autophagy would be difficult to evaluate. For the same reasons, we have used mice-fed chow diet and not HFD, in order to only evaluate the effect of central resistin without 
interference of metabolic or hormonal changes induced by HFD. However, as we have clearly established the role of central resistin, it would be interesting to evaluate resistin effects on HFD context in order to mimic the human situation. Furthermore, our investigation is also limited because we did not perform power analysis of the animals needed. Indeed, we have introduced the mice model in order to validate the direct resistin/TLR4 effects on hypothalamic autophagy. Thus, further experiments with more animals are needed to investigate the impact of HFD on hypothalamic resistin-dependent inhibition of autophagy. The implication of TLR4 as a negative regulator of autophagy has been previously reported at the cardiac level where TLR4 knockout promoted autophagy in a context of HFD (Hu \& Zhang 2017). Furthermore, we have previously demonstrated that resistin/TLR4 signaling pathway at the neuronal level directly activates inflammatory pathways such as JNK, p38 MAP kinase and induces IL6 and TNF $\alpha$ expression contributing to the low-grade inflammation (Benomar et al. 2013). This inflammatory status contributes to the deregulation of cellular energy homeostasis that is evidenced by a deep alteration of autophagy. However, one limitation of our study is that we cannot translate these findings to humans. Indeed, further in vivo experiments are needed for the translation of the results to the clinic.

In summary, our study reveals resistin/TLR4 signaling pathway as a novel mechanism for the negative regulation of autophagy at the neuronal and hypothalamic levels. Indeed, our findings clearly link resistin-induced lowgrade inflammation to the impairment of neuronal autophagy. In conclusion, our findings could contribute to the understanding of the underlying mechanisms linking neuroinflammation to the alteration of neuronal autophagy.

\section{Declaration of interest}

The authors declare that there is no conflict of interest that could be perceived as prejudicing the impartiality of the research reported.

\section{Funding}

This work is supported by the National Natural Science Foundation of China (Project \#81300725, M J). This work is also supported by the Centre National de la Recherche Scientifique (CNRS), the University of Paris-Sud and University of Paris-Saclay.

\section{Authors' contribution statement}

M T and J M conceived and designed the experiments; J M, Y B, S A R, G P, L R and D C performed experiments; M T and J M analyzed the data.
M T wrote the manuscript. All authors reviewed the manuscript prior to its submission.

\section{References}

Alers S, Loffler AS, Wesslborg S \& Stork B 2012 Role of AMPK-mTORULK1/2 in the regulation of autophagy: cross-talk, shortcuts, and feed-backs. Molecular and Cellular Biology 32 2-11. (https://doi. org/10.1128/MCB.06159-11)

Alirezaci M, Kemball CC, Flynn CT, Wood MR, Whitton JL \& Kiosses WB 2010 Short-term fasting induces profound neuronal autophagy. Autophagy 6 702-710. (https://doi.org/10.4161/auto.6.6.12376)

Benomar Y, Gertler A, De Lacy P, Crépin D, Ould Hamouda H, Riffault L \& Taouis M 2013 Central resistin overexposure induces insulin resistance through Toll-like receptor 4. Diabetes 62 102-114. (https:// doi.org/10.2337/db12-0237)

Benomar Y, Amine H, Crépin D, Al Rifai S, Riffault L, Gertler A \& Taouis M 2016 Central resistin/TLR4 impairs adiponectin signaling, contributing to insulin and FGF21 resistance. Diabetes 65 913-926. (https://doi.org/10.2337/db15-1029)

Bosch ME \& Kichian T 2015 Neuroinflammatory paradigms in lysosomal storage diseases. Frontiers in Neuroscience 9 417. (https://doi. org/10.3389/fnins.2015.00417)

Brunetti L, Orlando G, Recinella L, Michelotto B, Ferrante C \& Vacca M 2004 Resistin, but not adiponectin, inhibits dopamine and norepinephrine release in the hypothalamus. European Journal of Pharmacology 493 41-44. (https://doi.org/10.1016/j. ejphar.2004.04.020)

Cai D \& Lin T 2011 Hypothalamic inflammation: a double-edged sword to nutritional diseases. Annals of the New York Academy of Sciences 1243 E1-E39. (https://doi.org/10.1111/j.1749-6632.2011.06388.x)

De Lavera I, Pavon AD, Paz MV, Oropesa-Avila M, de la Mata M, AlcocerGomez E, Garrido-Maraver J, Cotan D, Alvarez-Cordoba M \& SanchezAlcazar JA 2017 The connections among autophagy, inflammasome and mitochondria. Current Drug Targets 18 1030-1038. (https://doi. org/10.2174/1389450117666160527143143)

Du L, Hickey RW, Bayir H, Watkins SC, Tyurin VA, Guo F, Kochanek PM, Jenkins LW, Ren J, Gibson G, et al. 2009 Starving neurons show sex difference in autophagy. Journal of Biological Chemistry 284 2383-2396. (https://doi.org/10.1074/jbc.M804396200)

Fahy D, Sanad MN, Duscha K, Lyons M, Lin F, Bozhkov P, Kunz HH, An J, Neuhans HE, Steel PG, et al. 2017 Impact of salt stress, cell death and autophagy on peroxisomes: quantitative and morphological analyses using small fluorescent probe N-BODIPY. Scientific Reports 739069. (https://doi.org/10.1038/srep39069)

Hu N \& Zhang Y 2017 TLR4 knockout attenuated high fat diet-induced cardiac dysfunction via NF-kB: JNK-dependent activation of autophagy. Biochimica et Biophysica Acta 1863 2001-2011. (https:// doi.org/10.1016/j.bbadis.2017.01.010)

Kahn BB \& Flier JS 2000 Obesity and insulin resistance. Journal of Clinical Investigation 151 4109-4115.

Lee JW, Park S, Takahashi Y \& Wang HG 2010 The association of AMPK with ULK1 regulates autophagy. PLoS ONE 5 e15394. (https://doi. org/10.1371/journal.pone.0015394)

Mizunoe Y, Sudo Y, Okita N, Hiraoka H, Mikami K, Narahara T, Nagishi A, Yoshida M, Higashibata R, Watanabe S, et al. 2017 Involvement of lysosomal dysfunction in autophagosome accumulation and early pathologies in adipose tissue of obese mice. Autophagy 13 642-653. (https://doi.org/10.1080/15548627.2016.1274850)

Mizushima N, Yamamato A, Matsui M, Yoshimori T, Ohsumi T \& Ohsumi Y 2004 In vivo analysis of autiophagy in response to nutrient starvation using transgenic mice expressing a fluorescent autophagosome marker. Molecular Biology of the Cell 15 1101-1111. (https://doi.org/10.1091/mbc.e03-09-0704) 
Mojiminiyi OA \& Abdella NA 2007 Association of resistin with inflammation and insulin resistance in patients with type 2 diabetes mellitus. Scandinavian Journal of Clinical and Laboratory Investigation 67 215-225. (https://doi.org/10.1080/00365510601032532)

Moller AB, Kampmann U, Hedegaard J, Thorsen K, Nordentoft I, Vendalbo, MH, Moller N \& Jessen N 2017 Altered gene expression and repressed markers of autophagy in skeletal muscle of insulin resistant patients with type 2 diabetes. Scientific Reports 2 43775. (https://doi. org/10.1038/srep43775)

Muse ED, Obici S, Bhanot S, Monia BP, McKay RA, Rajala NW, Scherer PE \& Rossetti L 2004 Role of resistin in diet-induced hepatic insulin resistance. Journal of Clinical Investigation 114 232-239. (https://doi. org/10.1172/JCI200421270)

Muse ED, Lam TK, Scherer PE \& Rossetti L 2007 Hypothalamic resistin induces hepatic insulin resistance. Journal of Clinical Investigation 117 1670-1678. (https://doi.org/10.1172/JCI30440)

Oh TS, Cho H, Cho JH, Yu SW \& Kim EK 2016 Hypothalamic AMPKinduced autophagy increases food intake by regulating NPY and POMC expression. Autophagy 11 2009-2025. (https://doi.org/10.1080/ 15548627.2016.1215382)

Olefsky JM \& Glass CK 2010 Macrophages, inflammation and insulin resistance. Annual Review of Physiology 72 219-246. (https://doi. org/10.1146/annurev-physiol-021909-135846)

Patel L, Buckels AC, Kinghorn IJ, Murdock PR, Holbrook JD, Plumpton C, Macphee CH \& Smith SA 2003 Resistin is expressed in human macrophages and directly regulated PPAR gamma activators. Biochemical and Biophysical Research Communications 300 472-476. (https://doi.org/10.1016/S0006-291X(02)02841-3)

Qi Y, Nie Z, Lee YS, Singhal NS, Scherer PE, Lazar MA \& Ahima RS 2006 Loss of resistin improves glucose homeostasis in leptin deficiency. Diabetes 55 3083-3090. (https://doi.org/10.2337/db05-0615)

Rajal MW, Obici S, Scherer PE \& Rossetti L 2003 Adipose derived resistin and gut-derived resistin-like molecule beta selectively impair insulin action on glucose production. Journal of Clinical Investigation $\mathbf{1 1 1}$ 225-230. (https://doi.org/10.1172/JCI16521)

Reilly MP, Lehrke M, Wolfe ML, Rohatgi A, Lazar MA \& Rader J 2005 Resistin is an inflammatory marker of atherosclerosis in humans. Circulation 111 932-939. (https://doi.org/10.1161/01. CIR.0000155620.10387.43)

Satoh H, Nguyen MT, Miles PD, Imamura T, Usui I \& Olefski JM 2004 Adenovirus-mediated chronic hyperresistinemia leads to in vivo insulin resistance in niormal rats. Journal of Clinical Investigation 114 224-231. (https://doi.org/10.1172/JCI20785)

Savage DB, Sewter CP, Klenk ES, Segal DG, Vidal-Puig A, Considine RV \& O'Rahilly S 2001 Resistin/Fizz3 expression in relation to obesity and peroxisome proliferator-activated receptor-gamma action in humans. Diabetes 50 2199-2202. (https://doi.org/10.2337/diabetes.50.10.2199)

Steppan CM, Bailey ST, Bhat S, Brown EJ, Banerjee RR, Wright CM, Patel HR, Ahima RS \& Lazar MA 2001 The hormone resistin links obesity to diabetes. Nature 409 307-312. (https://doi. org/10.1038/35053000)

Su P, Zhang J, Wang D, Zhao F, Cao Z, Aschner M \& Luo W 2016 The role of autophagy in modulation of neuroinflammation in microglia. Neuroscience 319 155-167. (https://doi.org/10.1016/j. neuroscience.2016.01.035)

Thaler JP \& Schwartz MW 2010 Inflammation and obesity pathogenesis: the hypothalamus heats up. Endocrinology 151 4109-4115. (https:// doi.org/10.1210/en.2010-0336)

Vasquez MJ, Gonzalez CR, Varela L, Lage R, Tovar S, Sangiao-Alvareillos S, Williams LM, Vidal-puig, A, Nogueiras, R, Lopez M, et al. 2008 Central resistin regulates hypothalamic and peripheral lipid metabolism in a nutritional dependent fashion. Endocrinology 149 4534-4543. (https:// doi.org/10.1210/en.2007-1708)

Wellen KE \& Hotamisligil GS 2003 Obesity-induced inflammatory changes in adipose tissue. Journal of Clinical Investigation 112 1785-1788. (https://doi.org/10.1172/JCI20514)

Wilkinson M, Wilkinson D, Wiesner G, Morash B \& Ur E 2005 Hypothalamic resistin immunoreactivity is reduced by obesity in the mouse: co-localization with alpha-melanocostimulating hormone. Neuroendocrinology 81 19-30. (https://doi. org/10.1159/000084871)

Yang L, Licastro D, Cave E, Veronese N, Spetta F, Rizza W, Bertozzi B, Villareal DT, Hotamisligil GS, Holloszy JD, et al. 2016 Long-term caloric restriction enhances cellular quality-control processes in human skeletal muscle. Cell Reports 14 422-428. (https://doi. org/10.1016/j.celrep.2015.12.042)

Yerra VG \& Kumar A 2017 Adenosine-monophosphate-activated protein kinase abates hyperglycemia-induced neuronal injury in experimental models of diabetic neuropathy: effect on mitochondrial biogenesis, autophagy and neuroinflammation. Molecular Neurobiology 54 2301-2312. (https://doi.org/10.1007/ s12035-016-9824-3)

Received in final form 15 May 2018

Accepted 17 May 2018

Accepted Preprint published online 17 May 2018
C) 2018 Society for Endocrinology Published by Bioscientifica Ltd. Printed in Great Britain 